OPEN ACCESS

Edited by:

Giuseppe Di Fede,

Istituto Neurologico Carlo Besta

(IRCCS), Italy

Reviewed by:

Efrat Levy,

School of Medicine, New York

University, United States

Maria Shadrina

Institute of Molecular Genetics (RAS),

Russia

*Correspondence

Luisa Benussi

Ibenussi@fatebenefratelli.eu

Specialty section:

This article was submitted to

Neurodegeneration,

a section of the journal

Frontiers in Neuroscience

Received: 20 September 2017 Accepted: 20 November 2017 Published: 01 December 2017

Citation:

Benussi L, Binetti $G$ and Ghidoni $R$ (2017) Loss of Neuroprotective Factors in Neurodegenerative

Dementias: The End or the Starting Point? Front. Neurosci. 11:672. doi: 10.3389/fnins.2017.00672

\section{Loss of Neuroprotective Factors in Neurodegenerative Dementias: The End or the Starting Point?}

\author{
Luisa Benussi $^{1 *}$, Giuliano Binetti ${ }^{1,2}$ and Roberta Ghidoni ${ }^{1}$ \\ ${ }^{1}$ Molecular Markers Laboratory, IRCCS Istituto Centro San Giovanni di Dio Fatebenefratelli, Brescia, Italy, ${ }^{2}$ MAC Memory \\ Center, IRCCS Istituto Centro San Giovanni di Dio Fatebenefratelli, Brescia, Italy
}

Recent clinical, genetic and biochemical experimental evidences highlight the existence of common molecular pathways underlying neurodegenerative diseases. In this review, we will explore a key common pathological mechanism, i.e., the loss of neuroprotective factors, across the three major neurodegenerative diseases leading to dementia: Alzheimer's disease (AD), Frontotemporal dementia (FTD) and Lewy body dementia (LBD). We will report evidences that the Brain Derived Neurotrophic Factor (BDNF), the most investigated and characterized brain neurotrophin, progranulin, a multi-functional adipokine with trophic and growth factor properties, and cystatin $\mathrm{C}$, a neuroprotective growth factor, are reduced in AD, FTD, and LBD. Moreover, we will review the molecular mechanism underlying the loss of neuroprotective factors in neurodegenerative diseases leading to dementia, with a special focus on endo-lysosomal pathway and intercellular communication mediated by extracellular vesicles. Exploring the shared commonality of disease mechanisms is of pivotal importance to identify novel potential therapeutic targets and to develop treatments to delay, slow or block disease progression.

Keywords: BDNF, progranulin, cystatin C, biomarkers, frontotemporal dementia, Alzheimer's disease, Lewy body dementia

\section{INTRODUCTION}

Neurodegenerative diseases leading to dementia are becoming increasingly prevalent throughout the world, due to the ageing of the human population, with an enormous economic impact (Wimo et al., 2013). Existing treatments are limited and mainly address the symptoms rather than the cause. In this context, the combined analysis of these diseases across traditional clinical boundaries may lead to a re-definition of clinical phenotypes and may highlight new possible therapeutic approaches.

In this review, we explore a key common pathological mechanism, i.e., the loss of neuroprotective factors (i.e., the Brain Derived Neurotrophic Factor, progranulin and cystatin C) across the three major neurodegenerative diseases leading to dementia: Alzheimer's disease (AD), Frontotemporal dementia (FTD) and Lewy body dementia (LBD).

In these disorders, monogenic forms due to a mutation in a single gene are described. However, a broad phenotypic expression variability between or even within pedigrees bearing the same mutation was found in many late onset monogenic neurodegenerative diseases (Finckh et al., 2000a; Binetti et al., 2003; Rademakers et al., 2007; Ghidoni et al., 2012a; Wauters et al., 2017). As we hypothesized "environmental/unidentified risk factors show an unexpected deterministic tendency to produce sporadic non-genetically determined forms of the disease in the vast majority of cases. 
The recognition that non-monogenic as well monogenic forms of dementia result substantially in the same disease, suggests that fundamental, simple mechanisms may underlie the apparent complexity of observed human neurodegenerative disorders" (Ghidoni et al., 2009). Abnormal protein accumulation characterizes the majority of neurodegenerative diseases thus leading to a classification based on the composition of the abnormal protein inclusions (Soto and Estrada, 2008). AD is characterized by deposition of beta-amyloid peptides (Abeta), phosphorylated tau protein and frequent alpha-synuclein deposits; LBD show alpha-synuclein positive deposits, while FTD present tau-positive and tau-negative, ubiquitin- and TDP-43-positive inclusions (Jellinger, 2008). It is also now clear that the protein aggregates spread from neuron to neuron contributing to the progression of the disease (Goedert, 2015).

Recent research has uncovered some of the mechanisms of the subcellular and extracellular distribution of neurotrophic factors and the molecular players involved in this process. In parallel, growing evidence suggested that endosomal and lysosomal dysfunction, or dysregulation in their trafficking, play an important role in neurodegeneration leading to dementia ( $\mathrm{Hu}$ et al., 2015). Moreover autophagy, a key intracellular degradation pathway, has also been implicated in neurodegeneration (Nixon, 2013). Exosomes, a specific subtype of extracellular vesicles of endosomal origin, are capable of transferring biomolecules between cells: By exposing cell-type-specific adhesion receptors, exosomes can interact with specific cells and deliver complex "signals", including proteins, lipids and RNA between cells. Several lines of evidence suggest a role for exosomes in neurodegenerative diseases (Rajendran et al., 2014). Since pathogenic proteins are released within exosomes, these vesicles have been suggested as "Trojan horses" of neurodegeneration (Ghidoni et al., 2008a). Conversely a loss of exosomes, might enhance neurodegeneration (Ghidoni et al., 2011; Benussi et al., 2016).

Exploring the shared commonality of disease mechanisms is of pivotal importance to identify novel potential therapeutic targets and to develop treatments to delay, slow or block disease progression. In this review we focused on the loss of neuroprotective factors in neurodegenerative dementias and on the cascades triggered by this loss.

\section{LOSS OF BRAIN DERIVED NEUROTROPHIC FACTOR IN ALZHEIMER'S DISEASE, FRONTOTEMPORAL DEMENTIA, LEWY BODY DEMENTIA}

Among neurotrophic factors, the Brain Derived Neurotrophic Factor (BDNF) has emerged as a major regulator of synaptic plasticity, neuronal survival and differentiation (Binder and Scharfman, 2004; Koshimizu et al., 2009). In animal models, it has been demonstrated that a reduction of BDNF seems to alter synaptic plasticity, long term potentiation and consequently impact on the formation and consolidation of memory (Linnarsson et al., 1997; Ma et al., 1998; Mu et al., 1999).
Converging human and preclinical studies suggest that loss of $\mathrm{BDNF}$ is involved in neurodegenerative dementias. In humans, the first evidence dates back to 1991, when a selective reduction of BDNF mRNA expression in the hippocampus in patients with AD was described (Phillips et al., 1991). Since then, a reduction of BDNF protein and mRNA expression have been consistently reported in AD brain (Connor et al., 1997; Hock et al., 2000; Holsinger et al., 2000; Michalski et al., 2015; Buchman et al., 2016) as well as in serum (Laske et al., 2007; Ventriglia et al., 2013; Siuda et al., 2017). A reduction of brain BDNF expression was demonstrated to correlate with the degree of cognitive decline not only in $\mathrm{AD}$, but also in subjects with mild cognitive impairment, in older adults and in the "oldest-old" (Peng et al., 2005; Michalski et al., 2015; Buchman et al., 2016). Altogether, these data suggest that BDNF decrease might be involved in the pathogenesis of $\mathrm{AD}$. A reduction of BDNF brain expression was also observed not only in $\mathrm{AD}$ but also in patients with different neurodegenerative disease, and specifically in other tauopathies, such as Pick's disease and corticobasal degeneration (Belrose et al., 2014). In parallel, an extensive analysis in different neurological diseases demonstrated a specific reduction of BDNF serum levels in FTD patients as well as in patients with LBD and vascular dementia (Ventriglia et al., 2013).

In the BDNF gene, a polymorphism causes a valine (Val) to methionine (Met) substitution at codon 66 (Val66Met), located in the BDNF pro-domain region. This variant is associated with altered protein intracellular trafficking and reduced secretion of BDNF (Egan et al., 2003; Chen et al., 2004; Chiaruttini et al., 2009). Increasing evidence suggests that the Val66Met variant is a genetic risk factor for AD (Ventriglia et al., 2002; Chen et al., 2014), even if case-control studies are not always consistent and a recent meta-analysis could not confirm this association (Zhao et al., 2017). However, a role of this polymorphism in dementia is supported by its association with cognitive decline and atrophy of the hippocampus in pre-stages of $\mathrm{AD}$ (Lim et al., 2014), including preclinical autosomal dominant AD (Lim et al., 2016). Recently, in a large longitudinal study on cognitively healthy individuals at risk for $\mathrm{AD}$, the BDNF Val66Met was demonstrated to predict cognitive decline due to $\mathrm{AD}$ (Boots et al., 2017). BDNF genetic variations were also associated with an increased risk of developing FTLD (Borroni et al., 2012). Specifically, in this study the BDNF Val66Met polymorphism was associated to a reduced hippocampus perfusion. Taken together, human studies suggested that a loss of BDNF may lead to vulnerability to dementia due to neurodegeneration, emphasizing the importance of BDNF as a potential pharmacological target (Nagahara and Tuszynski, 2011).

These evidences had led to preclinical studies in cellular and mouse disease models with the aim of better clarify the role of BDNF in neurodegeneration. Studies on $\mathrm{AD}$ models suggested that BDNF may moderate $\mathrm{AD}$ phenotype, and specifically (i) reduced Abeta accumulation, a hallmark feature of AD (Nagahara et al., 2009); rescued Abeta-mediated neuronal toxicity (Kimura et al., 2006; Nagahara et al., 2013); (ii) rescued Abeta-induced deficits in hippocampal synaptic plasticity (Zeng et al., 2010); and (iii) improved spatial learning 
and memory deficits (Blurton-Jones et al., 2009). Moreover, exogenous application of BDNF reduced Abeta production in primary neurons and in the brain of wild-type mice: this effect is mediated by the Sorting protein-related receptor with A-type repeats (SORLA), a sorting receptor for the amyloid precursor protein (APP) that regulates intracellular trafficking and APP cleavage to generate the Abeta peptide (Rohe et al., 2009). Accumulation of alpha-synuclein plays a key role in LBD (Spillantini and Goedert, 2016). It has been recently demonstrated that excessive accumulation of alpha-synuclein causes Rab proteins activations and consequently a strong endosomal dysfunction, that specifically impacts on trafficking and signaling of BDNF (Fang et al., 2017). Intriguingly, in a mouse model of $\mathrm{AD}$, a reduction of alpha-synuclein could mitigate neurodegeneration and recovered the levels of the Rab proteins, involved in BDNF intracellular trafficking (Spencer et al., 2016). Finally, in a mouse model of early tauopathy, the retina of human mutated $\mathrm{P} 301 \mathrm{~S}$ tau mice, the activity-dependent secretion of BDNF is impaired (Mazzaro et al., 2016). Taken together, preclinical studies on the role of $\mathrm{BDNF}$ in $\mathrm{AD}, \mathrm{LBD}$ and FTD, highlight an alteration of intracellular trafficking as a common molecular mechanism.

\section{LOSS OF CYSTATIN C IN ALZHEIMER'S DISEASE, FRONTOTEMPORAL DEMENTIA, LEWY BODY DEMENTIA}

Cystatin C, a cysteine protease inhibitor, is highly abundant in brain tissue and in the cerebrospinal fluid (CSF) (Löfberg and Grubb, 1979). In the brain, cystatin C plays neuroprotective roles in response to diverse neurotoxic conditions, via the inhibition of endosomal-lysosomal pathway cysteine proteases, such as cathepsins (Gauthier et al., 2011). In addition, glycosylated cystatin $\mathrm{C}$ was demonstrated to act as an autocrine/paracrine cofactor necessary for the proliferation of neuronal stem cells, both in vivo and in vitro (Taupin et al., 2000; Palmer et al., 2001); thus, we hypothesize that cystatin $\mathrm{C}$ also plays a protective role by supporting neuroregeneration (Benussi et al., 2006).

Molecular and clinical studies suggested that loss of cystatin $\mathrm{C}$ is involved in neurodegenerative dementias. In the cystatin $\mathrm{C}$ encoding gene (CST3) a rare haplotype (B haplotype) causes an Alanine (Ala) to Threonine (Thr) substitution at codon 25 (Ala25Thr), located in the cystatin $\mathrm{C}$ signal peptide. The CST3 B haplotype has been proposed as a risk factor for $\mathrm{AD}$, FTD, and LBD (Finckh et al., 2000b; Bertram et al., 2007; Benussi et al., 2010; Maetzler et al., 2010; Hua et al., 2012). The cystatin C B risk variant is processed less efficiently through the classical secretory pathway, resulting in its decreased secretion and intracellular accumulation (Benussi et al., 2003; Paraoan et al., 2004; Sant'Anna et al., 2016). Thus, a depletion of cystatin C might predispose CST3 B carriers to be more susceptible to neurodegeneration during lifetime. In line with this hypothesis, a reduction of CSF/plasma cystatin $\mathrm{C}$ was described in $\mathrm{AD}, \mathrm{FTD}$ as well as in LBD patients and it was associated with an anticipation of dementia onset (Rüetschi et al., 2005; Sundelöf et al., 2008;
Hansson et al., 2009; Ghidoni et al., 2010; Maetzler et al., 2010; Zhong et al., 2013).

In addition to being targeted to the classical secretory pathway, cystatin $\mathrm{C}$ is secreted in association with exosomes, a specific subtype of extracellular vesicles generated in late endosomes/multivesicular bodies (Ghidoni et al., 2011). We have demonstrated that the over-expression of familial AD-associated presenilin 2 mutations (i.e., PS2 M239I and PS2 T122R) resulted not only in a reduction of cystatin $\mathrm{C}$ secretion (Ghidoni et al., 2007) but also in a loss of native and glycosylated exosomal cystatin C (Ghidoni et al., 2011). Thus, the exosomal release of cystatin $\mathrm{C}$ might be an additional mechanism of cystatin $\mathrm{C}$-mediated protection that might be altered in $\mathrm{AD}$ and in other neurodegenerative disease. In transgenic models of $\mathrm{AD}$, modifications in cystatin $\mathrm{C}$ levels were demonstrated to affect amyloid deposition and impact on disease progression (Kaeser et al., 2007; Mi et al., 2007). Thus, low exosomal cystatin C levels might also result in a loss of inhibition of Abeta aggregation.

Cystatin C can activate autophagy both in physiological conditions and in response to neuronal cellular stress (Tizon et al., 2010) and to brain injury (Liu et al., 2014). In dementias the loss of cystatin C may also result in a loss of neuroprotection mediated by autophagy.

\section{LOSS OF PROGRANULIN IN ALZHEIMER'S DISEASE, FRONTOTEMPORAL DEMENTIA, LEWY BODY DEMENTIA}

Progranulin is a pleiotropic protein with multiple functions: it is a growth factor, it is variably expressed and processed in several organs-including brain-during the development and in the adult organism and plays a role in inflammation (Bateman and Bennett, 1998; Daniel et al., 2000, 2003; Zhu et al., 2002; Petkau et al., 2010). In the last years, multiple roles have been attributed to progranulin in the brain (e.g., neurite outgrowth, neuroinflammation, neuronal survival, microglial activation): even if progranulin has no exact homology with any other classical neurotrophic factor, it shows several qualitative similarities with them. Thus, the impact of progranulin shortage on the nervous system is subject of intensive research (Van Damme et al., 2008; Ghidoni et al., 2012a).

Shortage of progranulin-due to heterozygous null mutations in the progranulin gene $(G R N)$-is a frequent cause of frontotemporal dementia. In patients with familial FTD, the GRN mutation frequency can be up to $26 \%$ (Benussi et al., 2009). All the known heterozygous GRN mutations result in haploinsufficiency, due to mutant transcript degradation, (Baker et al., 2006; Cruts et al., 2006), leading to the reduction of plasma/serum and CSF progranulin protein in GRN-mutated subjects (Ghidoni et al., 2008b; Finch et al., 2009; Sleegers et al., 2009). In a multicenter study, we defined an optimal plasma progranulin cutoff value for predicting null progranulin mutations a cutoff level of $61.55 \mathrm{ng} / \mathrm{mL}$ identifies null mutation carriers (specificity: 99.6\%; sensitivity:95.8\%) among subjects attending to a memory clinic (Ghidoni et al., 2012b). The dosage of circulating progranulin sped up the identification of 
TABLE 1 | Summary of human studies demonstrating a loss of BDNF, cystatin C and progranulin as a common theme in AD, FTD, and LBD.

\begin{tabular}{|c|c|c|c|c|}
\hline & & \multicolumn{3}{|c|}{ Neuroprotective factor } \\
\hline & & BDNF & Cystatin C & Progranulin \\
\hline \multirow[t]{3}{*}{ Neurodegenerative dementia } & $A D$ & $\begin{array}{l}\text {-Decreased expression in brain } \\
\text {-Decreased BDNF serum level } \\
\text {-Genetic association (risk variant is } \\
\text { associated with a reduced BDNF } \\
\text { secretion) }\end{array}$ & $\begin{array}{l}\text {-Decreased serum levels } \\
\text {-Genetic association (risk variant is } \\
\text { associated with a reduced cystatin C } \\
\text { secretion) } \\
\text {-PS2 pathogenic mutations reduce protein } \\
\text { secretion }\end{array}$ & $\begin{array}{l}\text {-Pathogenic mutations in AD cases } \\
\text { (mutations cause loss of progranulin) } \\
\text {-Genetic association (risk variant is } \\
\text { associated with reduced progranulin } \\
\text { secretion) }\end{array}$ \\
\hline & FTD & $\begin{array}{l}\text {-Decreased expression in brain } \\
\text {-Decreased BDNF serum levels } \\
\text {-Genetic association (risk variant is } \\
\text { associated with a reduced BDNF } \\
\text { secretion) }\end{array}$ & $\begin{array}{l}\text {-Genetic association (risk variant is } \\
\text { associated with a reduced cystatin C } \\
\text { secretion) }\end{array}$ & $\begin{array}{l}\text {-Pathogenic mutations in many cases } \\
\text { (mutations cause loss of progranulin) } \\
\text {-Decreased progranulin CSF levels } \\
\text {-Genetic association (risk variant is } \\
\text { associated with reduced progranulin } \\
\text { secretion) }\end{array}$ \\
\hline & LBD & $\begin{array}{l}\text {-Decreased serum levels } \\
\text {-Alpha-synuclein accumulation } \\
\text { impairs BDNF trafficking and } \\
\text { secretion }\end{array}$ & $\begin{array}{l}\text {-Genetic association (risk variant is } \\
\text { associated with a reduced cystatin C } \\
\text { secretion) }\end{array}$ & $\begin{array}{l}\text {-Pathogenic mutations in LBD cases } \\
\text { (mutations cause loss of progranulin or } \\
\text { haploinsufficiency) }\end{array}$ \\
\hline
\end{tabular}

GRN mutations thus favoring genotype-phenotype correlation studies. In GRN null mutation carriers it has been demonstrated that the shortage of progranulin (i) invariably precedes clinical symptoms, since a reduction of protein is also measured in pre-symptomatic subjects (ii) is associated with multiple clinical presentations ranging from behavioral variant of frontotemporal dementia (bvFTD) (the most common clinical presentation), to primary progressive aphasia, corticobasal syndrome, AD, Parkinson's disease or dementia with Lewy bodies phenotype (Le Ber et al., 2008; Benussi et al., 2009; Arosio et al., 2013; Wauters et al., 2017).

Further, it has been demonstrated that some GRN missense mutations, associated with FTD and $\mathrm{AD}$, might lead to a partial loss of functional progranulin (Brouwers et al., 2008; Ghidoni et al., 2012b).

Interestingly, it has been recently described that CSF progranulin but not serum/plasma progranulin, is reduced also in $G R N$-negative FTD (Wilke et al., 2017): this reduction seems extend beyond the recognized modification of CSF progranulin levels by the SNP rs5848 (Nicholson et al., 2014) and it is not directly linked to tau alterations. The GRN rs5848 TT genotype is associated with reduced progranulin levels in FTD and AD (Rademakers et al., 2008; Hsiung et al., 2011) and has been described as risk factor for neurodegenerative diseases (Rademakers et al., 2008; Chen et al., 2015; Xu et al., 2017).

While heterozygous mutations result in adult onset FTD, the homozygous null mutations cause an early onset lysosomal storage disorder (Smith et al., 2012). In line with this observation, cutting edge molecular research suggests that progranulin is essential for proper lysosomal function and, as a consequence, a loss of progranulin might cause lysosomal dysfunction. Researchers demonstrated that (i) progranulin loss leads to progressive up-regulation of genes that control lysosomal functions and the innate immunity response and to profound microglia lysosomal defects that facilitate more efficient processing via the endolysosomal pathway (Lui et al., 2016); (ii) progranulin regulates lysosomal function and biogenesis through acidification of lysosomes (Tanaka et al., 2017); (iii) progranulin facilitates neuronal uptake and lysosomal delivery of prosaposin, the precursor of saposin peptides that are essential for lysosomal glycosphingolipids degradation (Zhou et al., 2017a); (iv) progranulin is a co-chaperone of HSP70 and plays an important role in beta-Glucocerebrosidase lysosomal localization (Jian et al., 2016): thus, loss of progranulin may directly affect the HSP70-based disaggregases leading to defects in the clearance of proteins associated with neurodegenerative diseases or indirectly affect the function of lysosomes resulting from the impairment of beta-Glucocerebrosidase lysosomal localization; (v) progranulin loss leads to an accumulation of polyunsaturated triacylglycerides, as well as a reduction of diacylglycerides and phosphatidylserines in fibroblast and enriched lysosome lipidomes (Evers et al., 2017); (vi) progranulin seems to promote TMEM106B degradation to maintain in the aged brain the physiological level of TMEM106B on lysosomal membranes; thus, shortage of progranulin results in accumulation of TMEM106B protein, which is accompanied by lysosomal abnormalities and lipofuscin accumulation (Zhou et al., 2017b); remarkably, TMEM106B deletion in GRN-/- mice normalizes lysosomal protein levels and rescues FTD-related behavioral abnormalities (Klein et al., 2017); (vii) in human primary fibroblasts from patients, progranulin loss alters exosome release and composition with an enrichment of the lysosomal marker Lamp1 (Benussi et al., 2016). 
Progranulin, a multifunctional growth factor, is secreted by the classical ER and/or Golgi secretory pathway (Ryan et al., 2009), it is incorporated into exosomes in a highly glycosylated form (Benussi et al., 2016) and it also ends up in lysosomes. Thus, progranulin seems to carry out both extracellular and endo-lysosomal functions.

\section{CONCLUDING REMARKS}

The loss of neuroprotective factors seems to be a common theme in AD, FTD. and LBD, as summarized in Table 1. Studies are numerous for $\mathrm{AD}$ and $\mathrm{FTD}$, but less investigation was done on LBD, especially regarding the level of cystatin C and progranulin in brain and biological fluids. Main evidences:

(i) Neuroprotective factors levels and neurodegenerative dementias: a reduction of BDNF, progranulin and cystatin $\mathrm{C}$ has been observed in $\mathrm{AD}, \mathrm{FTD}$, and LBD. In addition, low levels of BDNF correlate with the degree of cognitive decline and low levels of cystatin $\mathrm{C}$ are associated with an anticipation of dementia onset. Regarding progranulin, a clear link between progressive loss of expression and the clinical phenotype has been reported.

(ii) Genetic defects and neuroprotective factors levels: the BDNF and cystatin $\mathrm{C}$ risk variants are associated with an altered protein intracellular trafficking and secretion; moreover, BDNF polymorphism has been associated with cognitive decline and hippocampal atrophy in pre-stages of AD. The GRN rs5848 TT risk genotype is associated with reduced progranulin levels. GRN heterozygous loss of function mutations, a frequent cause of FTD and a rarer cause of
$\mathrm{AD} / \mathrm{LBD}$, are associated with a loss of at least $50 \%$ of progranulin protein.

(iii) Loss of neuroprotective factors and underlying molecular mechanisms: we know that "per se" to lose a neuroprotective factor is something bad. However, these factors seem to carry out both extracellular and intracellular functions: progranulin, for example, controls endo-lysosomal pathway, while cystatin $\mathrm{C}$ and $\mathrm{BDNF}$ reduce aggregation and deposition of Abeta peptides.

Thus, loss of neuroprotective factors may lead to a defect in proteins/peptides processing, degradation and aggregation. The answer to our question is: the loss of neuroprotective factors in neurodegenerative dementias might be the starting point, triggering endo-lysosomal dysfunctions leading to neurodegeneration.

\section{AUTHOR CONTRIBUTIONS}

LB, GB, RG: gave their substantial contribution to conception and design of the manuscript; and drafting the manuscript/revising it critically for important intellectual content. All authors have approved the manuscript in its present form for publication. All Authors agree to be accountable for all aspects of the work in ensuring that questions related to the accuracy or integrity of any part of the work are appropriately investigated and resolved.

\section{FUNDING}

This work was supported by Italian Ministry of Health (Ricerca Corrente and. NET 2011-02346784).

\section{REFERENCES}

Arosio, B., Abbate, C., Galimberti, D., Rossi, P. D., Inglese, S., Fenoglio, C., et al. (2013). GRN Thr272fs clinical heterogeneity: a case with atypical late onset presenting with a dementia with Lewy bodies phenotype. J. Alzheimers Dis. 35, 669-674. doi: 10.3233/JAD-130053

Baker, M., Mackenzie, I. R., Pickering-Brown, S. M., Gass, J., Rademakers, R., Lindholm, C., et al. (2006). Mutations in progranulin cause tau-negative frontotemporal dementia linked to chromosome 17. Nature 442, 916-919. doi: 10.1038/nature05016

Bateman, A., and Bennett, H. P. (1998). Granulins: the structure and function of an emerging family of growth factors. J. Endocrinol. 158, 145-151. doi: $10.1677 /$ joe. 0.1580145

Belrose, J. C., Masoudi, R., Michalski, B., and Fahnestock, M. (2014). Increased pro-nerve growth factor and decreased brain-derived neurotrophic factor in non-Alzheimer's disease tauopathies. Neurobiol. Aging 35, 926-933. doi: 10.1016/j.neurobiolaging.2013.08.029

Benussi, L., Binetti, G., and Ghidoni, R. (2006). "Cystatin C role in Alzheimer disease: from neurodegeneration to neuroregeneration," in Human Stefins and Cystatins, ed Nova Science Publishers, Inc. (New York, NY: Nova Science Publishers, Inc.), 115-125.

Benussi, L., Ciani, M., Tonoli, E., Morbin, M., Palamara, L., Albani, D., et al. (2016). Loss of exosomes in progranulin-associated frontotemporal dementia. Neurobiol. Aging 40, 41-49. doi: 10.1016/j.neurobiolaging.2016.01.001

Benussi, L., Ghidoni, R., Galimberti, D., Boccardi, M., Fenoglio, C., Scarpini, E., et al. (2010). The CST3 B haplotype is associated with frontotemporal lobar degeneration. Eur. J. Neurol. 17, 143-146. doi: 10.1111/j.1468-1331.2009.02767.x

Benussi, L., Ghidoni, R., Pegoiani, E., Moretti, D. V., Zanetti, O., and Binetti, G. (2009). Progranulin Leu271LeufsX10 is one of the most common FTLD and CBS associated mutations worldwide. Neurobiol. Dis. 33, 379-385. doi: 10.1016/j.nbd.2008.11.008

Benussi, L., Ghidoni, R., Steinhoff, T., Alberici, A., Villa, A., Mazzoli, F., et al. (2003). Alzheimer disease-associated cystatin C variant undergoes impaired secretion. Neurobiol. Dis. 13, 15-21. doi: 10.1016/S0969-9961(03)00012-3

Bertram, L., McQueen, M. B., Mullin, K., Blacker, D., and Tanzi, R. E. (2007). Systematic meta-analyses of Alzheimer disease genetic association studies: the AlzGene database. Nat. Genet. 39, 17-23. doi: 10.1038/ng1934

Binder, D. K., and Scharfman, H. E. (2004). Brain-derived neurotrophic factor. Growth Fact. 22, 123-231. doi: 10.1080/08977190410001723308

Binetti, G., Signorini, S., Squitti, R., Alberici, A., Benussi, L., Cassetta, E., et al. (2003). Atypical dementia associated with a novel presenilin-2 mutation. Ann. Neurol. 54, 832-836. doi: 10.1002/ana.10760

Blurton-Jones, M., Kitazawa, M., Martinez-Coria, H., Castello, N. A., Müller, F. J., Loring, J. F., et al. (2009). Neural stem cells improve cognition via BDNF in a transgenic model of Alzheimer disease. Proc. Natl. Acad. Sci. U.S.A. 106, 13594-13599. doi: 10.1073/pnas.0901402106

Boots, E. A., Schultz, S. A., Clark, L. R., Racine, A. M., Darst, B. F., Koscik, R. L., et al. (2017). BDNF Val66Met predicts cognitive decline in the Wisconsin Registry for Alzheimer's Prevention. Neurology 88, 2098-2106. doi: 10.1212/WNL.0000000000003980

Borroni, B., Bianchi, M., Premi, E., Alberici, A., Archetti, S., Paghera, B., et al. (2012). The brain-derived neurotrophic factor Val66Met polymorphism is associated with reduced hippocampus perfusion in frontotemporal lobar degeneration. J. Alzheimers Dis. 31, 243-251. doi: 10.3233/JAD-2012120226 
Brouwers, N., Sleegers, K., Engelborghs, S., Maurer-Stroh, S., Gijselinck, I., van der Zee, J., et al. (2008). Genetic variability in progranulin contributes to risk for clinically diagnosed Alzheimer disease. Neurology 71, 656-664. doi: 10.1212/01.wnl.0000319688.89790.7a

Buchman, A. S., Yu, L., Boyle, P. A., Schneider, J. A., De Jager, P. L., and Bennett, D. A. (2016). Higher brain BDNF gene expression is associated with slower cognitive decline in older adults. Neurology 86, 735-741. doi: 10.1212/WNL.0000000000002387

Chen, J., Liang, X., Li, B., Jiang, X., and Xu, Z. (2014). Gender-related association of brain-derived neurotrophic factor gene 196A/G polymorphism with Alzheimer's disease-a meta-analysis including 6854 cases and 6868 controls. Int. J. Neurosci. 124, 724-733. doi: 10.3109/00207454.2013.869594

Chen, Y., Li, S., Su, L., Sheng, J., Lv, W., Chen, G., et al. (2015). Association of progranulin polymorphism rs5848 with neurodegenerative diseases: a metaanalysis. J. Neurol. 262, 814-822. doi: 10.1007/s00415-014-7630-2

Chen, Z. Y., Patel, P. D., Sant, G., Meng, C. X., Teng, K. K., Hempstead, B. L., et al. (2004). Variant brain-derived neurotrophic factor (BDNF) (Met66) alters the intracellular trafficking and activity-dependent secretion of wild-type BDNF in neurosecretory cells and cortical neurons. J. Neurosci. 24, 4401-4411. doi: 10.1523/JNEUROSCI.0348-04.2004

Chiaruttini, C., Vicario, A., Li, Z., Baj, G., Braiuca, P., Wu, Y., et al. (2009). Dendritic trafficking of BDNF mRNA is mediated by translin and blocked by the G196A (Val66Met) mutation. Proc. Natl. Acad. Sci. U.S.A. 106, 16481-16486. doi: 10.1073/pnas.0902833106

Connor, B., Young, D., Yan, Q., Faull, R. L., Synek, B., and Dragunow, M. (1997). Brain-derived neurotrophic factor is reduced in Alzheimer's disease. Brain Res. Mol. Brain Res. 49, 71-81. doi: 10.1016/S0169-328X(97)00125-3

Cruts, M., Gijselinck, I., van der Zee, J., Engelborghs, S., Wils, H., Pirici, D., et al. (2006). Null mutations in progranulin cause ubiquitin-positive frontotemporal dementia linked to chromosome 17q21. Nature 442, 920-924. doi: $10.1038 /$ nature 05017

Daniel, R., Daniels, E., He, Z., and Bateman, A. (2003). Progranulin (acrogranin/PC cell-derived growth factor/granulin-epithelin precursor) is expressed in the placenta, epidermis, microvasculature, and brain during murine development. Dev. Dyn. 227, 593-599. doi: 10.1002/dvdy.10341

Daniel, R., He, Z., Carmichael, K. P., Halper, J., and Bateman, A. (2000). Cellular localization of gene expression for progranulin. J. Histochem. Cytochem. 48, 999-1009. doi: 10.1177/002215540004800713

Egan, M. F., Kojima, M., Callicott, J. H., Goldberg, T. E., Kolachana, B. S., Bertolino, A., et al. (2003). The BDNF val66met polymorphism affects activitydependent secretion of BDNF and human memory and hippocampal function. Cell 112, 257-269. doi: 10.1016/S0092-8674(03)00035-7

Evers, B. M., Rodriguez-Navas, C., Tesla, R. J., Prange-Kiel, J., Wasser, C. R., Yoo, K. S., et al. (2017). Lipidomic and transcriptomic basis of lysosomal dysfunction in progranulin deficiency. Cell Rep. 20, 2565-2574. doi: 10.1016/j.celrep.2017.08.056

Fang, F., Yang, W., Florio, J. B., Rockenstein, E., Spencer, B., Orain, X. M., et al. (2017). Synuclein impairs trafficking and signaling of BDNF in a mouse model of Parkinson's disease. Sci. Rep. 7:3868. doi: 10.1038/s41598-017-04 $232-4$

Finch, N., Baker, M., Crook, R., Swanson, K., Kuntz, K., Surtees, R., et al. (2009). Plasma progranulin levels predict progranulin mutation status in frontotemporal dementia patients and asymptomatic family members. Brain 132, 583-591. doi: 10.1093/brain/awn352

Finckh, U., Alberici, A., Antoniazzi, M., Benussi, L., Fedi, V., Giannini, C., et al. (2000a). Variable expression of familial Alzheimer disease associated with presenilin 2 mutation M239I. Neurology 54, 2006-2008. doi: 10.1212/WNL.54.10.2006

Finckh, U., von der Kammer, H., Velden, J., Michel, T., Andresen, B., Deng, A., et al. (2000b). Genetic association of a cystatin C gene polymorphism with late onset Alzheimer disease. Arch. Neurol. 57, 1579-1583. doi: 10.1001/archneur.57.11.1579

Gauthier, S., Kaur, G., Mi, W., Tizon, B., and Levy, E. (2011). Protective mechanisms by cystatin $\mathrm{C}$ in neurodegenerative diseases. Front. Biosci. (Schol. $E d)$. 3, 541-554. doi: 10.1016/j.arr.2016.06.003

Ghidoni, R., Benussi, L., and Binetti, G. (2008a). Exosomes: the Trojan horses of neurodegeneration. Med. Hypotheses. 70, 1226-1227. doi: 10.1016/j.mehy.2007.12.003
Ghidoni, R., Benussi, L., Glionna, M., Desenzani, S., Albertini, V., Levy, E., et al. (2010). Plasma cystatin C and risk of developing Alzheimer's disease in subjects with mild cognitive impairment. J. Alzheimers. Dis. 22, 985-991. doi: 10.3233/JAD-2010-101095

Ghidoni, R., Benussi, L., Glionna, M., Franzoni, M., and Binetti, G. (2008b). Low plasma progranulin levels predict progranulin mutations in frontotemporal lobar degeneration. Neurology 71, 1235-1239. doi: 10.1212/01.wnl.0000325058.10218.fc

Ghidoni, R., Benussi, L., Paterlini, A., Missale, C., Usardi, A., Rossi, R., et al. (2007). Presenilin 2 mutations alter cystatin $\mathrm{C}$ trafficking in mouse primary neurons. Neurobiol. Aging 28, 371-376. doi: 10.1016/j.neurobiolaging.2006.01.007

Ghidoni, R., Binetti, G., and Marcon, G. (2009). Late onset neurodegenerative diseases: a theoretical point of view. Med. Hypotheses. 72:102. doi: 10.1016/j.mehy.2008.08.014

Ghidoni, R., Paterlini, A., Albertini, V., Binetti, G., and Benussi, L. (2012a). Losing protein in the brain: the case of progranulin. Brain Res. 1476, 172-182. doi: 10.1016/j.brainres.2012.01.075

Ghidoni, R., Paterlini, A., Albertini, V., Glionna, M., Monti, E., Schiaffonati, L., et al. (2011). Cystatin C is released in association with exosomes: a new tool of neuronal communication which is unbalanced in Alzheimer's disease. Neurobiol. Aging 32, 1435-1442. doi: 10.1016/j.neurobiolaging.2009.08.013

Ghidoni, R., Stoppani, E., Rossi, G., Piccoli, E., Albertini, V., Paterlini, A., et al. (2012b). Optimal plasma progranulin cutoff value for predicting null progranulin mutations in neurodegenerative diseases: a multicenter Italian study. Neurodegener. Dis. 9, 121-127. doi: 10.1159/000333132

Goedert, M. (2015). Neurodegeneration. Alzheimer's and Parkinson's diseases: the prion concept in relation to assembled $\mathrm{A} \beta$, tau, and $\alpha$-synuclein. Science 349:1255555. doi: 10.1126/science. 1255555

Hansson, S. F., Andréasson, U., Wall, M., Skoog, I., Andreasen, N., Wallin, A., et al. (2009). Reduced levels of amyloid-beta-binding proteins in cerebrospinal fluid from Alzheimer's disease patients. J. Alzheimers Dis. 16, 389-397. doi: 10.3233/JAD-2009-0966

Hock, C., Heese, K., Hulette, C., Rosenberg, C., and Otten, U. (2000). Regionspecific neurotrophin imbalances in Alzheimer disease: decreased levels of brain-derived neurotrophic factor and increased levels of nerve growth factor in hippocampus and cortical areas. Arch. Neurol. 57, 846-851. doi: 10.1001/archneur.57.6.846

Holsinger, R. M., Schnarr, J., Henry, P., Castelo, V. T., and Fahnestock, M. (2000). Quantitation of BDNF mRNA in human parietal cortex by competitive reverse transcription-polymerase chain reaction: decreased levels in Alzheimer's disease. Brain Res. Mol. Brain Res. 76, 347-354. doi: 10.1016/S0169-328X(00)00023-1

Hsiung, G. Y., Fok, A., Feldman, H. H., Rademakers, R., and Mackenzie, I. R. (2011). rs5848 polymorphism and serum progranulin level. J. Neurol. Sci. 300, 28-32. doi: 10.1016/j.jns.2010.10.009

Hu, Y. B., Dammer, E. B., Ren, R. J., and Wang, G. (2015). The endosomallysosomal system: from acidification and cargo sorting to neurodegeneration. Transl. Neurodegener. 4:18. doi: 10.1186/s40035-015-0041-1

Hua, Y., Zhao, H., Lu, X., Kong, Y., and Jin, H. (2012). Meta-analysis of the cystatin C(CST3) gene G73A polymorphism and susceptibility to Alzheimer's disease. Int. J. Neurosci. 122, 431-438. doi: 10.3109/00207454.2012.672502

Jellinger, K. A. (2008). Neuropathological aspects of Alzheimer disease, Parkinson disease and frontotemporal dementia. Neurodegener. Dis. 5, 118-121. doi: $10.1159 / 000113679$

Jian, J., Tian, Q. Y., Hettinghouse, A., Zhao, S., Liu, H., Wei, J., et al. (2016). Progranulin recruits HSP70 to $\beta$-glucocerebrosidase and is therapeutic against gaucher disease. EBioMedicine 13, 212-224. doi: 10.1016/j.ebiom.2016.10.010

Kaeser, S. A., Herzig, M. C., Coomaraswamy, J., Kilger, E., Selenica, M. L., Winkler, D. T., et al. (2007). Cystatin C modulates cerebral beta-amyloidosis. Nat. Genet. 39, 1437-1439. doi: 10.1038/ng.2007.23

Kimura, N., Takahashi, M., Tashiro, T., and Terao, K. (2006). Amyloid beta upregulates brain-derived neurotrophic factor production from astrocytes: rescue from amyloid beta-related neuritic degeneration. J. Neurosci. Res. 84, 782-789. doi: 10.1002/jnr.20984

Klein, Z. A., Takahashi, H., Ma, M., Stagi, M., Zhou, M., Lam, T. T., et al. (2017). Loss of TMEM106B ameliorates lysosomal and frontotemporal dementiarelated phenotypes in progranulin-deficient mice. Neuron 95, 281-296.e6. doi: 10.1016/j.neuron.2017.06.026 
Koshimizu, H., Kiyosue, K., Hara, T., Hazama, S., Suzuki, S., Uegaki, K., et al. (2009). Multiple functions of precursor BDNF to CNS neurons: negative regulation of neurite growth, spine formation and cell survival. Mol. Brain 2:27. doi: 10.1186/1756-6606-2-27

Laske, C., Stransky, E., Leyhe, T., Eschweiler, G. W., Maetzler, W., Wittorf, A., et al. (2007). BDNF serum and CSF concentrations in Alzheimer's disease, normal pressure hydrocephalus and healthy controls. J. Psychiatr. Res. 41, 387-394. doi: 10.1016/j.jpsychires.2006.01.014

Le Ber, I., Camuzat, A., Hannequin, D., Pasquier, F., Guedj, E., Rovelet-Lecrux, A., et al. (2008). Phenotype variability in progranulin mutation carriers: a clinical, neuropsychological, imaging and genetic study. Brain 131, 732-746. doi: 10.1093/brain/awn012

Lim, Y. Y., Hassenstab, J., Cruchaga, C., Goate, A., Fagan, A. M., Benzinger, T. L., et al. (2016). BDNF Val66Met moderates memory impairment, hippocampal function and tau in preclinical autosomal dominant Alzheimer's disease. Brain 139, 2766-2777. doi: 10.1093/brain/aww200

Lim, Y. Y., Villemagne, V. L., Laws, S. M., Ames, D., Pietrzak, R. H., Ellis, K. A., et al. (2014). Effect of BDNF Val66Met on memory decline and hippocampal atrophy in prodromal Alzheimer's disease: a preliminary study. PLoS ONE 9:e86498. doi: 10.1371/journal.pone.0086498

Linnarsson, S., Björklund, A., and Ernfors, P. (1997). Learning deficit in BDNF mutant mice. Eur. J. Neurosci. 9, 2581-2587. doi: 10.1111/j.1460-9568.1997.tb01687.x

Liu, Y., Li, J., Wang, Z., Yu, Z., and Chen, G. (2014). Attenuation of early brain injury and learning deficits following experimental subarachnoid hemorrhage secondary to Cystatin C: possible involvement of the autophagy pathway. Mol. Neurobiol. 49, 1043-1054. doi: 10.1007/s12035-013-8579-3

Löfberg, H., and Grubb, A. O. (1979). Quantitation of gamma-trace in human biological fluids: indications for production in the central nervous system. Scand. J. Clin. Lab. Invest. 39, 619-626. doi: 10.3109/00365517909108866

Lui, H., Zhang, J., Makinson, S. R., Cahill, M. K., Kelley, K. W., Huang, H. Y., et al. (2016). Progranulin deficiency promotes circuit-specific synaptic pruning by microglia via complement activation. Cell 165, 921-935. doi: 10.1016/j.cell.2016.04.001

Ma, Y. L., Wang, H. L., Wu, H. C., Wei, C. L., and Lee, E. H. (1998). Brain-derived neurotrophic factor antisense oligonucleotide impairs memory retention and inhibits long-term potentiation in rats. Neuroscience 82, 957-967. doi: 10.1016/S0306-4522(97)00325-4

Maetzler, W., Schmid, B., Synofzik, M., Schulte, C., Riester, K., Huber, H., et al. (2010). The CST3 BB genotype and low cystatin C cerebrospinal fluid levels are associated with dementia in Lewy body disease. J. Alzheimers. Dis. 19, 937-942. doi: 10.3233/JAD-2010-1289

Mazzaro, N., Barini, E., Spillantini, M. G., Goedert, M., Medini, P., and Gasparini, L. (2016). Tau-driven neuronal and neurotrophic dysfunction in a mouse model of early tauopathy. J. Neurosci. 36, 2086-2100. doi: 10.1523/JNEUROSCI.0774-15.2016

Mi, W., Pawlik, M., Sastre, M., Jung, S. S., Radvinsky, D. S., Klein, A. M., et al. (2007). Cystatin C inhibits amyloid-beta deposition in Alzheimer's disease mouse models. Nat. Genet. 39, 1440-1442. doi: 10.1038/ng.2007.29

Michalski, B., Corrada, M. M., Kawas, C. H., and Fahnestock, M. (2015). Brainderived neurotrophic factor and TrkB expression in the "oldest-old," the $90+$ Study: correlation with cognitive status and levels of soluble amyloid-beta. Neurobiol. Aging 36, 3130-3139. doi: 10.1016/j.neurobiolaging.2015.08.022

Mu, J. S., Li, W. P., Yao, Z. B., and Zhou, X. F. (1999). Deprivation of endogenous brain-derived neurotrophic factor results in impairment of spatial learning and memory in adult rats. Brain Res. 835, 259-265. doi: 10.1016/S0006-8993(99)01592-9

Nagahara, A. H., Mateling, M., Kovacs, I., Wang, L., Eggert, S., Rockenstein, E., et al. (2013). Early BDNF treatment ameliorates cell loss in the entorhinal cortex of APP transgenic mice. J. Neurosci. 33, 15596-15602. doi: 10.1523/JNEUROSCI.5195-12.2013

Nagahara, A. H., Merrill, D. A., Coppola, G., Tsukada, S., Schroeder, B. E., Shaked, G. M., et al. (2009). Neuroprotective effects of brain-derived neurotrophic factor in rodent and primate models of Alzheimer's disease. Nat. Med. 15, 331-337. doi: 10.1038/nm.1912

Nagahara, A. H., and Tuszynski, M. H. (2011). Potential therapeutic uses of BDNF in neurological and psychiatric disorders. Nat. Rev. Drug Discov. 10, 209-219. doi: $10.1038 / \mathrm{nrd} 3366$
Nicholson, A. M., Finch, N. A., Thomas, C. S., Wojtas, A., Rutherford, N. J., Mielke, M. M., et al. (2014). Progranulin protein levels are differently regulated in plasma and CSF. Neurology 82, 1871-1878. doi: 10.1212/WNL.0000000000000445

Nixon, R. A. (2013). The role of autophagy in neurodegenerative disease. Nat. Med. 19, 983-997. doi: 10.1038/nm.3232

Palmer, T. D., Schwartz, P. H., Taupin, P., Kaspar, B., Stein, S. A., and Gage, F. H. (2001). Cell culture. Progenitor cells from human brain after death. Nature 411, 42-43. doi: 10.1038/35075141

Paraoan, L., Ratnayaka, A., Spiller, D. G., Hiscott, P., White, M. R., and Grierson, I. (2004). Unexpected intracellular localization of the AMD-associated cystatin C variant. Traffic 5, 884-895. doi: 10.1111/j.1600-0854.2004.00230.x

Peng, S., Wuu, J., Mufson, E. J., and Fahnestock, M. (2005). Precursor form of brain-derived neurotrophic factor and mature brain-derived neurotrophic factor are decreased in the pre-clinical stages of Alzheimer's disease. J. Neurochem. 93, 1412-1421. doi: 10.1111/j.1471-4159.2005.03135.x

Petkau, T. L., Neal, S. J., Orban, P. C., MacDonald, J. L., Hill, A. M., Lu, G., et al. (2010). Progranulin expression in the developing and adult murine brain. J. Comp. Neurol. 518, 3931-3947. doi: 10.1002/cne.22430

Phillips, H. S., Hains, J. M., Armanini, M., Laramee, G. R., Johnson, S. A., and Winslow, J. W. (1991). BDNF mRNA is decreased in the hippocampus of individuals with Alzheimer's disease. Neuron 7, 695-702. doi: 10.1016/0896-6273(91)90273-3

Rademakers, R., Baker, M., Gass, J., Adamson, J., Huey, E. D., Momeni, P., et al. (2007). Phenotypic variability associated with progranulin haploinsufficiency in patients with the common 1477C-> T (Arg493X) mutation: an international initiative. Lancet Neurol. 6, 857-868. doi: 10.1016/S1474-4422(07)70221-1

Rademakers, R., Eriksen, J. L., Baker, M., Robinson, T., Ahmed, Z., Lincoln, S. J., et al. (2008). Common variation in the miR-659 binding-site of GRN is a major risk factor for TDP43-positive frontotemporal dementia. Hum. Mol. Genet. 17, 3631-3642. doi: 10.1093/hmg/ddn257

Rajendran, L., Bali, J., Barr, M. M., Court, F. A., Krämer-Albers, E. M., Picou, F., et al. (2014). Emerging roles of extracellular vesicles in the nervous system. J. Neurosci. 34, 15482-15489. doi: 10.1523/JNEUROSCI.3258-14.2014

Rohe, M., Synowitz, M., Glass, R., Paul, S. M., Nykjaer, A., and Willnow, T. E. (2009). Brain-derived neurotrophic factor reduces amyloidogenic processing through control of SORLA gene expression. J. Neurosci. 29, 15472-15478. doi: 10.1523/JNEUROSCI.3960-09.2009

Rüetschi, U., Zetterberg, H., Podust, V. N., Gottfries, J., Li, S., Hviid Simonsen, A., et al. (2005). Identification of CSF biomarkers for frontotemporal dementia using SELDI-TOF. Exp. Neurol. 196, 273-281. doi: 10.1016/j.expneurol.2005.08.002

Ryan, C. L., Baranowski, D. C., Chitramuthu, B. P., Malik, S., Li, Z., Cao, M., et al. (2009). Progranulin is expressed within motor neurons and promotes neuronal cell survival. BMC Neurosci. 10:130. doi: 10.1186/1471-2202-10-130

Sant'Anna, R., Navarro, S., Ventura, S., Paraoan, L., and Foguel, D. (2016). Amyloid properties of the leader peptide of variant B cystatin C: implications for Alzheimer and macular degeneration. FEBS Lett. 590, 644-654. doi: 10.1002/1873-3468.12093

Siuda, J., Patalong-Ogiewa, M., Zmuda, W., Targosz-Gajniak, M., Niewiadomska, E., Matuszek, I., et al. (2017). Cognitive impairment and BDNF serum levels. Neurol. Neurochir. Pol. 51, 24-32. doi: 10.1016/j.pjnns.2016.10.001

Sleegers, K., Brouwers, N., Van Damme, P., Engelborghs, S., Gijselinck, I., van der Zee, J., et al. (2009). Serum biomarker for progranulinassociated frontotemporal lobar degeneration. Ann. Neurol. 65, 603-609. doi: 10.1002/ana.21621

Smith, K. R., Damiano, J., Franceschetti, S., Carpenter, S., Canafoglia, L., Morbin, M., et al. (2012). Strikingly different clinicopathological phenotypes determined by progranulin-mutation dosage. Am. J. Hum. Genet. 90, 1102-1107. doi: 10.1016/j.ajhg.2012.04.021

Soto, C., and Estrada, L. D. (2008). Protein misfolding and neurodegeneration. Arch. Neurol. 65, 184-189. doi: 10.1001/archneurol.2007.56

Spencer, B., Desplats, P. A., Overk, C. R., Valera-Martin, E., Rissman, R. A., and $\mathrm{Wu}, \mathrm{C}$. (2016). Reducing endogenous $\alpha$-synuclein mitigates the degeneration of selective neuronal populations in an Alzheimer's disease transgenic mouse model. J. Neurosci. 36, 7971-7984. doi: 10.1523/JNEUROSCI.0775-16.2016

Spillantini, M. G., and Goedert, M. (2016). Synucleinopathies: past, present and future. Neuropathol. Appl. Neurobiol. 42, 3-5. doi: 10.1111/nan.12311 
Sundelöf, J., Arnlöv, J., Ingelsson, E., Sundström, J., Basu, S., Zethelius, B., et al. (2008). Serum cystatin C and the risk of Alzheimer disease in elderly men. Neurology 71, 1072-1079. doi: 10.1212/01.wnl.0000326894.40353.93

Tanaka, Y., Suzuki, G., Matsuwaki, T., Hosokawa, M., Serrano, G., Beach, T. G., et al. (2017). Progranulin regulates lysosomal function and biogenesis through acidification of lysosomes. Hum. Mol. Genet. 26, 969-988. doi: $10.1093 / \mathrm{hmg} / \mathrm{ddx} 011$

Taupin, P., Ray, J., Fischer, W. H., Suhr, S. T., Hakansson, K., Grubb, A., et al. (2000). FGF-2-responsive neural stem cell proliferation requires CCg, a novel autocrine/paracrine cofactor. Neuron 28, 385-397. doi: 10.1016/S0896-6273(00)00119-7

Tizon, B., Sahoo, S., Yu, H., Gauthier, S., Kumar, A. R., Mohan, P., et al. (2010). Induction of autophagy by cystatin C: a mechanism that protects murine primary cortical neurons and neuronal cell lines. PLoS ONE 5:e9819. doi: 10.1371/journal.pone.0009819

Van Damme, P., Van Hoecke, A., Lambrechts, D., Vanacker, P., Bogaert, E., van Swieten, J., et al. (2008). Progranulin functions as a neurotrophic factor to regulate neurite outgrowth and enhance neuronal survival. J. Cell Biol. 181, 37-41. doi: $10.1083 /$ jcb.200712039

Ventriglia, M., Bocchio Chiavetto, L., Benussi, L., Binetti, G., Zanetti, O., Riva, M. A., et al. (2002). Association between the BDNF $196 \mathrm{~A} / \mathrm{G}$ polymorphism and sporadic Alzheimer's disease. Mol. Psychiatry 7, 136-137. doi: 10.1038/sj.mp.4000952

Ventriglia, M., Zanardini, R., Bonomini, C., Zanetti, O., Volpe, D., Pasqualetti, P., et al. (2013). Serum brain-derived neurotrophic factor levels in different neurological diseases. Biomed. Res. Int. 2013:901082. doi: 10.1155/2013/901082

Wauters, E., Van Mossevelde, S., Van der Zee, J., Cruts, M., and Van Broeckhoven, C. (2017). Modifiers of GRN-Associated frontotemporal lobar degeneration. Trends Mol. Med. 23, 962-979. doi: 10.1016/j.molmed.2017.08.004

Wilke, C., Gillardon, F., Deuschle, C., Hobert, M. A., Jansen, I. E., Metzger, F. G., et al. (2017). Cerebrospinal fluid progranulin, but not serum progranulin, is reduced in GRN-negative frontotemporal dementia. Neurodegener. Dis. 17, 83-88. doi: 10.1159/000448896

Wimo, A., Jönsson, L., Bond, J., Prince, M., Winblad, B., and Alzheimer Disease International (2013). The worldwide economic impact of dementia 2010. Alzheimers Dement. 9, 1-11.e3. doi: 10.1016/j.jalz.2012.11.006

Xu, H. M., Tan, L., Wan, Y., Tan, M. S., Zhang, W., Zheng, Z. J., et al. (2017). PGRN is associated with late-onset Alzheimer's disease: a casecontrol replication study and meta-analysis. Mol. Neurobiol. 54, 1187-1195. doi: 10.1007/s12035-016-9698-4
Zeng, Y., Zhao, D., and Xie, C. W. (2010). Neurotrophins enhance CaMKII activity and rescue amyloid-beta-induced deficits in hippocampal synaptic plasticity. J. Alzheimers Dis. 21, 823-831. doi: 10.3233/JAD-2010-100264

Zhao, Q., Shen, Y., Zhao, Y., Si, L., Jiang, S., Qiu, Y., et al. (2017). Val66Met polymorphism in BDNF has no sexual and APOE $\varepsilon 4$ status-based dimorphic effects on susceptibility to Alzheimer's disease: evidence from an updated metaanalysis of case-control studies and high-throughput genotyping cohorts. Am. J. Alzheimers Dis. Other Demen doi: 10.1177/1533317517733037. [Epub ahead of print].

Zhong, X. M., Hou, L., Luo, X. N., Shi, H. S., Hu, G. Y., He, H. B., et al. (2013). Alterations of CSF cystatin C levels and their correlations with CSF $\mathrm{A} \beta 40$ and $\mathrm{A} \beta 42$ levels in patients with Alzheimer's disease, dementia with Lewy bodies and the atrophic form of general paresis. PLoS ONE 8:e55328. doi: 10.1371/journal.pone.0055328

Zhou, X., Sun, L., Bracko, O., Choi, J. W., Jia, Y., Nana, A. L., et al. (2017a). Impaired prosaposin lysosomal trafficking in frontotemporal lobar degeneration due to progranulin mutations. Nat. Commun. 8:15277. doi: $10.1038 /$ ncomms 15277

Zhou, X., Sun, L., Brady, O. A., Murphy, K. A., and Hu, F. (2017b). Elevated TMEM106B levels exaggerate lipofuscin accumulation and lysosomal dysfunction in aged mice with progranulin deficiency. Acta Neuropathol. Commun. 5:9. doi: 10.1186/s40478-017-0412-1

Zhu, J., Nathan, C., Jin, W., Sim, D., Ashcroft, G. S., Wahl, S. M., et al. (2002). Conversion of proepithelin to epithelins: roles of SLPI and elastase in host defense and wound repair. Cell 111, 867-878. doi: 10.1016/S0092-8674(02)01141-8

Conflict of Interest Statement: The authors declare that the research was conducted in the absence of any commercial or financial relationships that could be construed as a potential conflict of interest.

The handling Editor declared a past co-authorship with several of the authors LB, GB, RG.

Copyright (c) 2017 Benussi, Binetti and Ghidoni. This is an open-access article distributed under the terms of the Creative Commons Attribution License (CC BY). The use, distribution or reproduction in other forums is permitted, provided the original author(s) or licensor are credited and that the original publication in this journal is cited, in accordance with accepted academic practice. No use, distribution or reproduction is permitted which does not comply with these terms. 